\title{
THE NEW EU REGULATION ON ONLINE RESOLUTION FOR CONSUMER DISPUTES
}

\author{
by \\ MICHAEL BOGDAN ${ }^{*}$
}

This paper deals with the central provisions of the new EU Regulation No 524/2013 on Online Dispute Resolution for Consumer Disputes, which will apply from 9 January 2016. The purpose of the Regulation is to create a European userfriendly interactive website ("ODR platform") for out-of-court, independent, impartial, inexpensive and fast resolution of disputes stemming from online sale or service contracts between a consumer resident in the EU and a trader established in the EU. The paper presents the principal features of the Regulation and discusses its potential contribution to improved functioning of the EU internal market.

\section{KEY WORDS}

Alternative dispute resolution, Consumer disputes, European Union, Online dispute resolution

The European Union (EU) aspires, among other things, to create an internal consumer market comprising an area without internal frontiers in which the free movement of goods and services is assured. Nevertheless, a significant portion - about twenty percent - of consumers experience problems in connection with cross-border purchases of goods and services within the EU. The fear of these problems, in combination with the expectation that cross-border consumer disputes cannot be resolved in a simple, inexpensive and fair manner, makes consumers reluctant to make purchases in other Member States. This widely spread lack of confidence constitutes an obstacle to economic growth and deprives the consumers of the benefits of a

Professor of Law, University of Lund. E-mail: michael.bogdan@jur.lu.se. This paper constitutes an amended version of a presentation made by the author in November 2014 at the Cyberspace 2014 Conference in Brno. 
more efficient competition offered by the internal market in terms of a greater selection of goods and services and lower prices.

The EU has made some efforts to make court procedures more suitable for cross-border consumer disputes, for example, by the creation of a simplified and less expensive procedure for small claims. ${ }^{1}$ Many Member States have also introduced various forms of alternative out-of-court dispute resolution (ADR), which has grown in frequency and importance. For example, in many countries there are various public or private consumer complaint boards. Some of them cover the whole consumer market while others specialize in disputes in a certain branch, such as the travel industry; some can only make recommendations while others can impose binding solutions. In order to make ADR easier to use, the EU has recently issued two pieces of relevant legislation, namely Directive 2013/11 on consumer $\mathrm{ADR}^{2}$ and Regulation No 524/2013 on online dispute resolution (ODR) for consumer disputes. ${ }^{3}$ Both instruments were published in the Official Journal of the European Union on the same day, i.e. on 18 June 2013. The ADR Directive must be transposed into national law of the Member States by 9 July 2015 and the ODR Regulation will become applicable six months later, i.e. from 9 January 2016. As the two instruments are not yet applicable, there is so far no practical experience of their functioning.

In a journal devoted to law and technology issues, it is of course mainly the Regulation on consumer ODR that is of interest, as it focuses on consumer dispute resolution online. However, the ODR Regulation is interconnected with the Directive on consumer ADR. To put it simply, the ODR Regulation constitutes a complement to the ADR Directive and must be read in conjunction with it. The ADR Directive could function even without the ODR Regulation, but the ODR Regulation could not work without the ADR Directive.

It is, consequently, necessary to begin by presenting the main features of the ADR Directive, which purports to make high-quality consumer ADR widely available by ensuring that consumers can, on a voluntary basis,

1 See Regulation No 861/2007 of 11 July 2007 establishing a European Small Claims Procedure, Official Journal of the European Union 2007 L 199 p. 1.

2 See Directive 2013/11 of 21 May 2013 on Alternative Dispute Resolution for Consumer Disputes, Official Journal of the European Union 2013 L 165 p. 63.

3 See Regulation No 524/2013 of 21 May 2013 on Online Dispute Resolution for Consumer Disputes, Official Journal of the European Union 2013 L 165 p. 1. 
submit complaints against traders to entities offering, as formulated in the Directive's Article 1, “independent, impartial, transparent, effective, fast and fair ADR procedures", without however depriving the parties of their right of access to the normal judicial system. The Directive is a "minimum directive" and does not stand in the way of a more far-reaching consumer protection. The Directive also leaves it in the competence of Member States to determine whether ADR entities established in their territories can make recommendations only or have the power to impose solutions binding on the parties. The Directive applies to both domestic and cross-border disputes stemming from contracts between a trader established in the EU and a consumer resident in the EU, but it does not provide for recognition and enforcement of binding ADR decisions made in another Member State (such decisions, by definition, are not made by courts and do not therefore fall within the scope of, for example, the Brussels Ia Regulation ${ }^{4}$ or the above-mentioned Regulation establishing a European Small Claims Procedure). The Directive excludes procedures initiated by a trader against a consumer (Article 2).

Article 5 of the Directive obliges the Member States to ensure that consumer disputes involving a trader established on their respective territories can be submitted to an "ADR entity" which complies with the Directive's requirements, such as the necessary accessibility, expertise, independence, impartiality, transparency, effectiveness, fairness and legality. For example, with regard to effectiveness Article 8 requires that the outcome of the ADR procedure be made available within a period of ninety calendar days from the date on which the ADR entity has received the complete complaint file, even though in the case of highly complex disputes that period can be extended. With regard to legality, I cannot fail to mention that Article 11 of the Directive deals with the issue of conflict of laws. It refers to the conflict rules on consumer contracts in Article 6 of the EU Rome I Regulation ${ }^{5}$ and states that if the ADR procedure aims at resolving the dispute by imposing a solution binding on the consumer, that solution must not deprive the consumer of the protection afforded to him by the

4 See Regulation No 1215/2012 of 12 December 2012 on Jurisdiction and the Recognition and Enforcement of Judgments in Civil and Commercial Matters (recast), Official Journal of the European Union 2012 L 351 p. 1.

5 See Regulation No 593/2008 of 17 June 2008 on the Law Applicable to Contractual Obligations, Official Journal of the European Union 2008 L 177 p. 6. 
mandatory rules of the law of the Member State in which he is habitually resident.

Pursuant to Articles 18-20, each Member State must designate a "competent authority" which, among other things, will assess, on the basis of the information it has received from entities wishing to qualify as ADR entities under the Directive, whether they in fact do fulfill the Directive's above-mentioned requirements. Information about the approved entities is notified to the Commission, which will establish and publish on its website a consolidated and updated list of such entities, including information about their contact details, fees (only symbolical fees are allowed), language or languages they use, the types of disputes they cover, the binding or nonbinding nature of their decisions, whether the entity may refuse to deal with a given dispute, etc. Each national competent authority will on its own website provide a link to this list.

Turning to the ODR Regulation, it must be repeated that it builds further on the rules in the ADR Directive. Pursuant to its Article 2(1), the Regulation applies to the out-of-court resolution of disputes, concerning contractual obligations stemming from online sales or service contracts between a consumer resident in the EU and a trader established in the EU, through the intervention of an ADR entity listed in accordance with the ADR Directive.

Just like the ADR Directive, the ODR Regulation applies to both domestic and cross-border situations, even though it will be particularly useful in cross-border electronic commerce (e-commerce). ${ }^{6}$ In some other respects, the scope of the Regulation differs from that of the Directive. To begin with, the Regulation applies only to disputes arising out of contracts made online, defined in Article 4(1)(e) as sales or service contracts where the trader, or the trader's intermediary, has offered goods or services on a website or by other electronic means and the consumer has ordered such goods or services on that website or by other electronic means. It is thus the on-line conclusion of the contract rather than the on-line performance that is decisive for the applicability of the Regulation. Furthermore, in spite of the Regulation's heading speaking about "online dispute resolution", the Regulation does not require that the ADR procedure as such, after the

\footnotetext{
It is worth noting that the legal basis of the ODR Regulation is not Article 81 of the Treaty on the Functioning of the European Union (TFEU), dealing with judicial cooperation in civil matters having cross-border implications, but Article 114, dealing with the approximation of laws for the purpose of establishing a functioning internal market.
} 
competent ADR entity has been determined, be conducted through the ODR platform (Article 10(d)).

Another important difference between the ADR Directive and the ODR Regulation is that the Regulation in principle applies also to procedures initiated by a trader against a consumer, even though only to the extent the legislation of the Member State of the consumer allows for such disputes to be resolved by an ADR entity (Article 2(2)).

The main contribution of the Regulation is that it will lead to the creation of an online "platform". To put it simply, this platform is nothing else than an interactive website which can be accessed and used, free of charge, by both consumers and traders, for the purpose of making it easier to identify and get in touch with an ADR entity approved under the ADR Directive. ${ }^{7}$

The platform will be developed and operated by the Commission. In accordance with Article 5(4), the platform will have a number of functions, such as to provide an electronic complaint form to be filled in and submitted online, to inform the respondent party about the complaint, to assist the parties to identify the competent ADR entities and transmit the complaint to the agreed entity, to offer a free-of-charge electronic case management tool which will enable (but not compel) both parties and the ADR entity to conduct the dispute resolution online, etc. The platform will operate in all official languages of the EU and offer an electronic translation function capable of translating the exchanged information necessary for the resolution of the dispute. It will, furthermore, provide information and an online guide to help the parties.

Information about the existence of the platform and a link to it must be provided in the general terms and conditions and on the websites of all traders and marketplaces established within the EU and engaging in online sales of goods or services, as well as in contract offers made by e-mail (Article 14). Furthermore, Member States are obliged to "encourage" consumer and business associations to provide an electronic link to the ODR platform. The ODR platform will, in turn, publish the list of ADR entities listed pursuant to the ADR Directive.

The Regulation contains rather detailed provisions on the submission, transmission and processing of a complaint. I can present them here in an extremely simplified manner only. Article 9 of the Regulation requires the

7 During a discussion about the ODR Regulation, one participant referred to it as a "dating service" between the parties and an appropriate ADR entity. 
ODR platform to transmit, without delay and in an easily understandable way, the fully completed electronic complaint form to the respondent party, together with information that the parties must agree on an ADR entity in order for the complaint to be transmitted to it and that, if no agreement is reached by the parties or no competent ADR entity is identified, the complaint will not be processed. The platform will also provide information about competent ADR entities to choose from, including their contact details, whether they charge any fees (the use of the platform itself is free of charge), what language(s) they use, the average length of the ADR procedure, whether the outcome of the procedure is binding or not, etc. The platform will invite the respondent to state within ten days whether he is willing to use any such entity or is committed to use any particular entity. Upon receipt of the respondent's answer, the platform communicates the information to the complainant.

I cannot help mentioning a rather peculiar provision in Article 8(5) of the Regulation. It stipulates that only data which are accurate, relevant and not excessive in relation to the purpose for which they are collected shall be processed through the electronic complaint form and its attachments. The legal value of this provision is in my view doubtful. When there is a conflict between the parties, they usually hold diverging views about the accuracy and relevance of submitted data. In any case, these matters cannot be left to the electronic ODR platform to decide.

If the parties have agreed to use an ADR entity, the platform will automatically and without delay transmit the complaint to it. The agreed upon ADR entity will then without delay inform the parties about whether it agrees or refuses to deal with the dispute. If, on the other hand, the parties fail to agree on an ADR entity within thirty calendar days after the submission of the complaint, or if the entity refuses to deal with the dispute, the complaint will not be processed any further and the complainant party will be informed that he has to look for some other means of redress (such as turning to a court of law).

As mentioned above, the ADR entity, which has agreed to deal with a dispute in accordance with the Regulation, is not required to conduct the following ADR procedure as such through the ODR platform but can use more traditional methods in accordance with its national law. However, it must not require the physical presence of the parties or their 
representatives, unless its procedural rules provide for that possibility and the parties agree.

By referring to Article 8 of the ADR Directive, the ODR Regulation requires the ADR entity dealing with a dispute to conclude the procedure within ninety calendar days from the date on which the ADR entity has received the complete complaint file, even though that deadline is extendable in the case of highly complex disputes.

Pursuant to Article 18, Member States are obliged to introduce effective, proportionate and dissuasive penalties applicable to infringements of the Regulation. There are additional provisions, dealing with matters such as confidentiality and processing of personal data, but they cannot be dealt with here in detail. It suffices to mention that access to the Commission's database, storing information related to the disputes, will be granted only to the ADR entity concerned and that personal data will be kept in the database only for the time necessary for its purpose and shall be automatically deleted, at the latest, six months after the date of conclusion of the dispute. This retention period will also apply to personal data kept in national files by the ADR entities or the ODR contact points, unless longer retention periods are provided for by national law.

The Regulation stresses the importance of the platform being userfriendly and, as far as possible, being usable by all, including vulnerable users. I suppose that when Article 5(1) speaks of vulnerable users ("design for all"), it has in mind mainly consumers living with various kinds of disabilities, but I sincerely hope that elderly consumers, such as the author of these lines, who do not feel comfortable with complicated online transactions, are not forgotten either. In any case, pursuant to Article 6, the Commission must, by 9 January 2015, test the technical functionality and user-friendliness of the ODR platform and report the result to the European Parliament and to the Council. Each Member State is obliged, pursuant to Article 7, to designate an "ODR contact point" hosting at least two "advisors", who will provide explanations, support and assistance to the parties wishing to make use of the platform, but the ODR contact points are not obliged to perform these tasks in the case of disputes where both parties are habitually resident in the same Member State.

In conclusion, I must say I am impressed by how much of the "secretarial" management of the ADR proceedings is entrusted to computers by the ODR Regulation. Let us hope the system will work 
smoothly from the very beginning. On the other hand, we all have experience of the programming errors and other unpredictable problems ("infant diseases") that tend to occur in connection with the introduction of new electronic systems, or upgrading of already existing systems. To make the platform so user-friendly that it can really be used even by unsophisticated consumers will be a difficult task. Lodging a consumer complaint is a rare event in the life of most of the consumers, which is fortunate in one way, but it also means that few of them will ever acquire experience enabling them to use the ODR portal as a matter of routine. Employing the services of a hired professional lawyer, even though not forbidden, would go against the whole idea of consumer ADR. On the other hand, the advisors attached to the state-appointed "ODR contact points" will hopefully provide useful support, and it should also be recalled that the ODR Regulation applies only to consumer disputes arising out of contracts made online, so the consumers involved are normally not quite inexperienced Internet-users. Furthermore, the use of the ODR will not be compulsory, so that the less computer-savvy consumers - but also small traders - will not be left without access to the more traditional forms of $\mathrm{ADR}$, as regulated by the ADR Directive.

\section{LIST OF REFERENCES}

Regulation No 861/2007 of 11 July 2007 establishing a European Small

Claims Procedure, Official Journal of the European Union 2007 L 199 p. 1.

Directive 2013/11 of 21 May 2013 on Alternative Dispute Resolution for Consumer Disputes, Official Journal of the European Union 2013 L 165 p. 63.

Regulation No 524/2013 of 21 May 2013 on Online Dispute Resolution for Consumer Disputes, Official Journal of the European Union 2013 L 165 p. 1.

Regulation No 1215/2012 of 12 December 2012 on Jurisdiction and the Recognition and Enforcement of Judgments in Civil and Commercial Matters (recast), Official Journal of the European Union 2012 L 351 p. 1. 
Regulation No 593/2008 of 17 June 2008 on the Law Applicable to Contractual Obligations, Official Journal of the European Union 2008 L 177 p. 6. 